Volume, 13, n. 2, ano, 2017

\title{
MULHER, MATÉRIA ANIMAL E IN-DIFERENÇA
}

Andreia C. Marin. ${ }^{1}$

Eduardo Silveira. ${ }^{2}$

Stheffany C Martins. ${ }^{3}$

\begin{abstract}
RESUMO: O tema é a superação das determinações e das dualidades que justificam o discurso sobre as diferenças. Com esse objetivo, citamos a ideia de indiferença, no lugar de identificação, na oposição à diferença, conforme estudos antropológicos. Falamos sobre as tramas que servem de sustentação a um discurso de separação entre natureza e cultura e de submissão do animal e da mulher, destacando o corpo produtor nas imagens da artista plástica cubana Ana Mendieta.
\end{abstract}

Palavras-chave: Diferença. Mulher. Animalidade. Corpo.

ABSTRACT: The theme is the overcoming of the determinations and dualities that justify the discourse on the differences. With this purpose, we cite the idea of indifference, instead of identification, in opposition to difference, according to anthropological studies. We talk about the wefts that support a discourse of separation between nature and culture and submission of the animal and the woman, highlighting the productive body in the images of the cuban plastic artist Ana Mendieta.

Key-words: Difference. Woman. Animality.Body.

\section{Itinerários}

\subsection{Envolta, nua}

É porque estou segura que ganho a liberdade de dançar, é porque não tenho medo que improviso, é porque ignoro a rotina que me entrego ao fulgor. A dança é isso, um modo mais intenso de existir. As árvores dançam, as folhas dançam, a chuva dança, os animais dançam, o sol e a lua dançam. Tudo o que há a fazer é deixar-se puxar para dentro de seu círculo, deixar-se sugar sem medo para dentro da órbita desmesurada das coisas. Então a vida começa a passar por nós e inclui-nos e nós baixamos a cabeça e dizemos "sim" e dançamos. (GERSÃO, 2004, p.25).

Escandalosamente. [...] Curiosos.

Tentei evitar, mas não deu.

\footnotetext{
1 Professora Adjunta do Instituto de Educação, Letras, Artes e Ciências Humanas e Sociais/UFTM Grad.Biologia/USP - Filosofia/UFPR. Dra. Ecologia/UFSCar. aamarinea@ gmail.com

${ }^{2}$ Professor de Biologia - Instituto Federal de Santa Catarina (IFSC) Doutorado em Educação - UFSC - Mestrado em Educação - UFPR - Graduação em Ciências Biológicas - UFPR

e-mail para contato: eduardosilveira@ifsc.edu.br

${ }^{3}$ Graduanda em História - Universidade Federal do Triângulo Mineiro stheffanycruvinel@ hotmail.com
} 
REVISTAELETRÔNICA

DA GRADUAÇÃO/PÓS-GRADUAÇÃO EM EDUCAÇÃ O

ISSN. 1807-9342

Volume, 13, n. 2, ano, 2017

A coisa toda começava a desenrolar no centro do meu corpo em movimentos inevitáveis.

E o ponto que ia, em espiral, se revelando em linhas, inicialmente concêntricas, depois irritantemente em curvas sem direção, estava na parte onde se mostra o meu sexo.

E logo, os pudores... Reprovadores...

Mas eu jurava que tinha ali a veste que envolvia os quadris inquietos. Mas, não, não, não. Simplesmente não podiam enxergar.

Uma linha rebelde subiu pelo abdômen e foi desenhando o redondo do seio esquerdo. Depois do direito. E eis aí. Também não podiam ver o azul do véu que os envolviam cariciosamente.

Eu, transtornada, na performance inevitável...

E foram-se as linhas e suas vidas próprias... E desobedientes às curvas... E alimentadas de forças estranhas...

Formaram pernas, pés... Eu pisava uma fina plataforma de cortiça, mas eles se espantavam porque viam somente pés flutuantes...

E os braços eram, ora fortes e harmoniosos, ora como galhos de árvores embalados pelo vento.

As linhas forçavam a reta contínua do pescoço, mas tudo que conseguiam eram riscos de mãos trêmulas. A imprecisão aumentando quando, em ritmo meio alucinado, começaram a se entrecruzar disformemente desenhando uma teia emaranhada que ocupou o lugar da minha cabeça.

Os outros, olhando espantados e com ares de um certo temor... Eu jurava que havia sobre a confusa massa uma membrana de lucidez e, em sua superfície, um rosto reconhecidamente comum... Mas, não, não, não... Eles não podiam ver...

Exposta assim, eu lutei alguns segundos com minha velha clareza e intencionalmente ajeitei as vestes na tentativa de torná-las visíveis. Mas, um olhar sutil ao canto dos olhos me levou para a pequena fresta de espelho que me devolveu, sorrateiro, o reflexo. Nele eu só via as linhas reveladoras...

Fiz pequenos movimentos provocando, nelas, ondas reverberantes e demorou minutos para que voltassem ao pulsante estacionário. E dancei novamente brincando com o cinéticopotencial que desenhava, a cada vez, um emaranhado diferente no reflexo.

Estava envolta somente em tramas, sem vestes. E as livres sensações nunca mais evitadas. 
Volume, 13, n. 2, ano, 2017

\title{
1.2.Matéria animal
}

\begin{abstract}
Isso, entre outras coisas, eu aprendi com a África: a pequenez do ser humano, diante da vastidão do que não é humano. Não somos nada, poeira no vento, silhuetas minúsculas, na imensidão da paisagem.

Basta-nos, no fundo, muito pouco, porque somos também pouco: matar a fome, a sede e o desejo de sexo, a esteira para dormir e o coração em paz. (GERSÃO, 2004, p.161)
\end{abstract}

Um corpo humano se curva... Toca o chão, quadrúpede... Já se transmutou em bicho. A pele do animal sobre o corpo nu. Um corpo nu de uma fêmea humana... (San Felipe, Fotografia de Ana Mendieta, 1973).

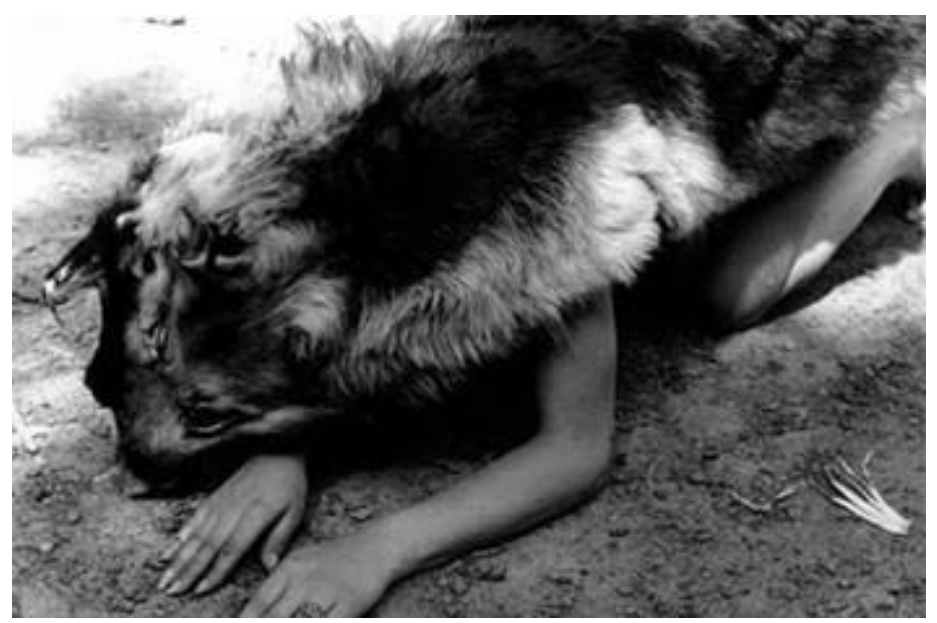

Fig.1. Fotografia de Ana Mendieta, San Felipe, 1973. In: http://filamentosmovimentos.blogspot.com.br

Em outra cena - ave - o corpo empresta suas esquecidas formas humanas ao deviranimal, coberto de penas. Denunciam sua natureza monte de vênus e vulva expostas (MENDIETA, Featherson a woman, 1972).

O corpo da fêmea humana continua nu... Tão nu quanto o animal em sacrifício que ela segura,agonizante, dispostoante seu sexo. Rito de sangue e morte (MENDIETA,ChickenPiece, 1972).

O sangue também escorre sobre a pele do mesmo corpo nu, tingindo suas nádegas e coxas, colocados em destaque na cena. Corpo reclinado sobre a mesa, estuprado (MENDIETA, RapeScene, 1973).

Covas na terra, aberturas inusitadas. São úteros, ou túmulos (HEARTNEY,2004). Vaginas, ou portais. 
REVISTAELETRÔNICA DA GRADUAÇÃO/PÓS-GRADUAÇÃO EM EDUCAÇÃ O

ISSN. 1807-9342

Volume, 13, n. 2, ano, 2017

O corpo da fêmea, nu, aceita sua finitude e entrega-se ao jogo do aniquilamento em chamas. Restam cinzas impressas na paisagem (MENDIETA, Silueta de Cenizas, 1975).

É um corpo artista... Foi um desejo de libertaçõesprotagonizado porAna Mendieta, uma força denunciadora do mais próprio do humano: suas ingênuas intenções de um para além. De todas as coisas que os humanos quiseram superar, a pura animalidade foi a que mais o desafiou. Está na base de seus mais primitivos e persistentes temores: a desrazão; a morte; a selvageria; a reprodução sem finalidade; enfim, um estar no mundo como um animal, desprovido de projetos existenciais e de convicções, um reduzir-se a uma morte animalesca.

A materialidade de sua incontornável condição foi dada à visibilidade no corpo nu de Mendieta, nas múltiplas formas que ela imprimiu na paisagem, nas cenas onde abraça seus esqueletos, onde cava nas paisagens a impressão de seus contornos, na sua entrega sem resistências ao movimento das águas, nas silhuetas delineadas pelas cinzas.

O corpo parece não ser apenas performático: ele tem a propriedade de uma matéria desprendida das representações cristalizadas que justificam o pensamento dual e, inclusive, a incoerência das palavras necessárias às práticas linguageiras deste texto... Ele não tem a ver com a oposição entre humanos e animais, como também não tem qualquer afinidade com os nomes que o definem como nu, feminino ou que o qualificam de vulnerável, manipulável por outros corpos semelhantes. Não é um corpo comprometido com o "entre", o "além", o "igual" ou "diferente"... É um corpo dado ao compartilhamento. É pertencente à terra, à árvore, à morte. Ele está estendido sobre esqueletos, copulando com a finitude, sem dramas. A existência é ele mesmo, cravado na materialidade do mundo. Sua única objeção é àquilo que se apropria de forças violentas contra o corpo próprio, justificadas em uma cultura que, de há muito, constituiu-se como recusa ingênua do incontornável pacto com a natureza.

Não parece também apenas um corpo feminista. Há um enigma na pele desse corpo: não serve, conformada, às identificações; aceita conjugar-se com outras peles; força a invisibilidade de vestes sobrepostas; transmuta-se, escapa.

Nas imagens de Silueta Series (MENDIETA, 1978), o corpo está nu, recusando a conformação de uma biopolítica que organiza a natureza em uma contenção moral, negando sua nudez, exigindo artifícios pelos quais se possa admiti-lo em uma normalidade, como que mascarando sua animalidade. A silhueta formada pelas flores, plantas, penas, que lhe serviriam de adorno, é desnudada pelas águas e se dissolve na paisagem. 
Volume, 13, n. 2, ano, 2017

\section{Reflexões}

\subsection{Transmutação}

Vem comigo, disse a formiga desaparecendo na terra.

Canta mais alto, disse a cigarra.

Entra em mim, disse a árvore. Eu te levo, disse o vento.

[...] Ficava-se muito tempo debaixo da árvore, encostado ao tronco, e, como eu disse, a gente transformava-se em árvores. Ou também em pássaro, embora voar fosse mais difícil. Mas ser as coisas era fácil. Porque de repente se tinha na mão a raiz de tudo o que era vivo. (GERSÃO, 2004, p.18).

Não fosse darmo-nos um nome atrelado a um conceito radicalmente diferencial dos demais viventes talvez não consolidássemos a lógica da distinção e não inaugurássemos um irrefreável vício em identificação. E se assim se desse, não estaríamos tão artificialmente colocados para além do animal, do corpo e talvez não tivéssemos nos equivocado sobre o substrato dos nossos discursos: a distinção entre natureza e cultura.

Quando o humano se define como o ser que transcende a base natural de sua existência, não só determina um espaço próprio para si como também constitui o Outro, personificação de sua diferença. O Outro é sempre um determinado visto pela percepção de quem o identifica numa imediata distinção: "a relação com o Outro é um drama: a existência do Outro é uma ameaça, um perigo. A velha filosofia grega, que nesse ponto Platão não desmente, mostrou que a alteridade é a mesma coisa que a negação" (BEAUVOIR, 1970, p. 100-101).

Animais são os Outros para os humanos. Tudo que está colocado a seu lado tende também à outridade, à negação. Talvez seja ainda cedo para adentrarmos na questão da superação da dualidade mulher-natureza versus homem-cultura, mas certamente teremos que encará-la, uma vez que esteve, durante muito tempo, fundando nossos discursos sobre gênero. Vale, no entanto, sinalizar: mulheres são a outridade para os homens e vice-versa. "A mulher apresentava-se assim como o inessencial que nunca retorna ao essencial, como o Outro absoluto, sem reciprocidade" (BEAUVOIR, 1970, p.181). Se a determinação do Outro não cessa na evidência do compartilhamento, há sempre o risco de uma hierarquização nas relações.

Assertiva heideggeriana: está vedada, ao humano, a transposição para outros viventes (HEIDEGGER, 2006). Recuperamos essa consideração de um destaque que Valentim (2012, pp.12-13) faz de questões apresentadas por Heidegger em Os Conceitos Fundamentais da Metafísica: i) "podemos nos transpor para o animal?"; ii) "podemos nos transpor para uma pedra?" O comentador apresenta as respostas, nos seguintes termos: "Heidegger conclui respondendo que a segunda pergunta é 'fundamentalmente impossível' e faticamente (faktisch) 
REVISTAELETRÔNICA

DA GRADUAÇÃO/PÓS-GRADUAÇÃO EM EDUCAÇÃ O

Volume, 13, n. 2, ano, 2017

ISSN. 1807-9342

'sem sentido'. Quanto à primeira, responde que a transposição do homem para o animal é possível, em nada contrassensual, sendo, porém, 'questionável' a sua realização fática". O evidente na assertiva diz respeito à lógica ancorada na sistemática de viventes alocada nos limites entre os "sem cultura" e "com cultura". Ocorre que essa não é a única lógica que circula entre as mentes dos denominados humanos.

Diferentemente do dualismo moderno que distribui humanos e não humanos em dois domínios ontológicos mais ou menos estanques, as cosmologias amazônicas estabelecem uma diferença de grau, não de natureza, entre os homens, as plantas e os animais (DESCOLA, 1998, p.26).

Descola (1998; 2006) apresenta, como exemplo dessas cosmologias, os Achuar da Amazônia equatoriana, para os quais plantas e animais possuem uma faculdade similar à alma humana, dotando-os de intencionalidade e consciência, o que impede imediatamente a negação de pessoalidade aos viventes não humanos. Na obra As lanças do crepúsculo (DESCOLA, 2006), o autor chama a atenção para a capacidade de experimentar emoções e de se comunicar com os humanos e outras espécies delegada aos animais e plantas.

Admitindo a pessoalidade de animais e plantas, é preciso considerar a possibilidade de uma comunicação com eles, o que os Achuar fazem na forma dos anent, rituais e encantamentos mágicos, com os quais se estabelece uma linguagem comum, incluindo nela os seres sobrenaturais. A hierarquia entre os sujeitos baseia-se muito mais na capacidade de comunicação do que em uma essência diferencial. Valentim (2012,p.16) destaca as definições dadas por Viveiros de Castro para o xamanismo, exemplo dessa comunicação: "arte política de comutação entre perspectivas, capaz de promover uma comunicação transversal entre incomunicáveis"ou "habilidade manifesta por certos indivíduos de cruzar deliberadamente as barreiras corporais e adotar a perspectiva de subjetividades aloespecíficas, de modo a administrar as relações entre estas e os humanos".

Descolas detalha as distinções entre os indivíduos considerando essa diferença comunicativa:

Os animais, e as plantas em menor medida, são aí percebidos como sujeitos sociais, dotados de instituições e de comportamentos perfeitamente simétricos àqueles dos homens. Além disso, os seres do cosmos definem-se menos por uma essência abstrata ou por uma faculdade particular (a presença ou ausência de linguagem, por exemplo, ou de consciência reflexiva e emoções) do que pelas posições que ocupam uns em relação aos outros, seja em função de características de seu metabolismo e, principalmente, de seu regime alimentar, seja em nome do tipo de comunicação em que são reputados capazes de se engajar. (DESCOLAS, 1998, p.27). 
REVISTA LLETRÔNICA

DA GRADUAÇÃO/PÓS-GRADUAÇÃO EM EDUCAÇÃ O

ISSN. 1807-9342

Volume, 13, n. 2, ano, 2017

Para além da possibilidade de comunicação, há uma radicalidade ainda maior no perspectivismo: a possibilidade de uma mesma natureza por trás de toda variedade de forma dos viventes. Viveiros de Castro (1996, p.116) comenta que "a forma manifesta de cada espécie é um mero envelope (uma 'roupa') a esconder uma forma interna humana, normalmente visível apenas aos olhos da própria espécie ou de certos seres transespecíficos, como os xamãs”. A materialização dessa subjetividade em uma forma corporal, característica de cada espécie, não seria um atributo fixo, mas sim uma "roupa" descartável:

A noção de "roupa" é uma das expressões privilegiadas da metamorfose - espíritos, mortos e xamãs que assumem formas animais, bichos que viram outros bichos, humanos que são inadvertidamente mudados em animais - um processo onipresente no "mundo altamente transformacional" (RIVIËREapudVIVEIROS DE CASTRO, 1996, p.117)

Essa possibilidade de transposição entre diferentes viventes, antes impedida na ontologia heideggeriana, desconstrói a dicotomia entre natureza e cultura, ao mesmo tempo em que enfraquece a ideia de essência e de fundamento, abrindo espaço para a noção de devir. Não haveria, aí, espaço para a defesa de identidades fixas, uma vez que as relações entre viventes e entidades prevê a possibilidade de mutações e metamorfoses.

\footnotetext{
Ao contrário do dualismo moderno, que desdobra uma multiplicidade de diferenças culturais sobre o fundo de uma natureza imutável, o pensamento ameríndio encara o cosmos inteiro como animado por um mesmo regime cultural, diversificado não tanto por naturezas heterogêneas quanto por modos diferentes de se apreender uns aos outros. [...] Plantas e animais são interlocutores legítimos; a despeito das aparências enganadoras, eles não vivem em um plano ontológico distinto daquele dos humanos (DESCOLAS, 1998, p.28).

Enquanto nós tendemos a conceber a ação de relacionar como um descarte das diferenças em favor das similaridades, o pensamento indígena vê o processo de um outro ângulo: o oposto da diferença não é a identidade, mas a indiferença (VIVEIROS DE CASTROapud VALENTIM, 2012, p.22).
}

O motivo de transitarmos na fronteira entre animal humano e animal não humano parece evidenciar-se: um suposto ponto de partida comum para muitas dualidades, separatismos, perfeitamente descoladas de uma realidade onde só existiriam compartilhamentos. Nesse cenário, o próprio conceito de diferença precisa ser relativizado, já que não seriam necessárias identificações para proporcionar a estabilidade e a legitimidade do diferente, mas sim um cancelamento do regime de negações que justificam a distinção, uma aceitação incondicional dos estados de indiferença, ou ainda a percepção de um processo permanente de indiferenciação.

Há, ainda, um interesse específico na questão, a saber, o fato de ser o corpo de uma fêmea humana - de Mendieta-colocado em evidência na proximidade com o animal, em uma 
REVISTAELETRÔNICA

DA GRADUAÇÃO/PÓS-GRADUAÇÃO EM EDUCAÇÃ O

ISSN. 1807-9342

Volume, 13, n. 2, ano, 2017

proximidade que o lança aos mesmos riscos que o corpo do animal, imersos na lógica da diferença radical: a submissão, o sacrifício, a natureza. Não é estranho que seja uma fêmea humana a sinalizar para a fragilidade das representações sobre o animal e sobre a mulher, afinal, se já julgamos ter superado a distinção entre natureza e cultura, falta conseguirmos ler, no exercício da alteridade, a extinção de seus efeitos, sem o que o conceito de mulher ainda estará impedindo as subjetivações para além do conceito. Compartilhamento, transmutação são provocações interessantes nesse sentido.Mendieta provoca a visibilidade da transmutação quando se conforma à roupa do animal, denuncia as pressões do sacrifício do próprio corpo (SCHMIDT, 2010), na cena de estupro, e do corpo animal submetido, na performance onde segura uma ave agonizante diante da própria nudez.

Queremos falar sobre o corpo no regime de indiferenciação, mas pelos efeitos históricos do regime de representação e de exclusão, teremos que evidenciar os conceitos a serem superados. No caso específico das presentes reflexões, o conceito de mulher, colocado no reflexo das consequências do conceito de animal. Aproximar a mulher do animal não é aqui, reforcemos, a reafirmação da separação entre natureza e cultura, mas a denúncia de que ambos sofrem as consequências dessa distinção enraizada nas representações sociais. Embora sutilizadas pelos contextos atuais de emancipação feminina e dos movimentos de defesa do abolicionismo animal, essa representações guardam os resquícios da mesma lógica de exclusão que aproximou historicamente mulher e animal. Podemos, nesse sentido, citar Cidre que lembra que muitas mulheres foram igualadas a animais nos rituais de sacrifício, havendo uma inequívoca simbologia que aproxima o sangue da mulher e do animal.

ser vertida enlaejecución de unsacrificio. Enlastragedias, laanimalización de lospersonajesfemeninoscontribuye a la peculiar relaciónentablada entre mujeres y sacrificio: lasociedadgriegaantiguaplantea una concepción de lamujer que hace de su sangre particularmente apta para son concomitantemente animalizadas y convertidas envíctimaspropiciatorias. (CIDRE, 2014, p.19).

\subsection{A velha e não esquecida questão: natureza-mulher}

O que é a mulher? Com que se parece? Para que serve?... Perguntas da tarefa de qualquer sistemata.

Todo esforço de determinação é um artifício humano, do qual resulta uma zona limítrofe entre o ser supostamente transcendente e aqueles determinados. Uma vez constituídas representações do outro como diferença radical, instala-se a dificuldade de reconhecimento de 


\section{ITHERARIUS REFLECTIONIS}

Volume, 13, n. 2, ano, 2017
DA GRADUAÇÃO/PÓS-GRADUAÇÃO EM EDUCAÇÃ O

ISSN. 1807-9342

uma zona de compartilhamento, de percepção das múltiplas intersecções que há naquilo que distanciamos pelos binômios que constituem a diferença. Daí, a dificuldade na compreensão de que a distinção entre natureza e cultura não passa de um artifício intelectual.

A identificação de outras dualidades associadas a essa distinção entre natureza e cultura dá pista dos efeitos problemáticos da naturalização da representação como síntese totalizante. Entre elas, já destacamos aqui, a separação entre humanos e não humanos, que se traduz na dualidade humanidade-animalidade, e a sua tão discutida derivação: a aproximação da mulher da zona limítrofe entre humano e animal.

Na década de setenta, o pool de ideias dos movimentos feministas recebeu de Sherry Ortner o texto Está a mulher para o homem assim como a natureza para a cultura?. Nele, Ortner (1979) desenvolve justamente, na esteira das provocações de Beauvoir (1970) em $O$ segundo sexo, a análise da aproximação entre a mulher e a natureza e entre o homem e a cultura, como se, de fato, o destino da mulher fosse o biológico, dando mera sustentação às invenções existenciais e sociais dos homens. Obviamente, não pretendemos reproduzir aqui essas mesmas provocações, até porque a própria Ortner não o faria, como declara em entrevista cedida recentemente onde comenta as ideias expostas na obra (DEBERT e ALMEIDA, 2006, p. 440441). Reconhece ali alguma radicalização e um risco desnecessário, quer seja, o de reforçar, ao contrário de sua intenção, a suposta dualidade que, para além das diferenças inquestionáveis entre homens e mulheres, serviria mais como justificação para limitar os papéis femininos na vida e na sociedade, que propriamente para suscitar alguma ruptura possível da mulher diante dos discursos de sua contenção.

A despeito, porém, da autocrítica exposta pela pensadora na referida entrevista, há, suspeitamos, vários elementos nas obras tanto de Beauvoir como dela própria, que guardam relativo grau de pertinência para nossos dias. Além dessas reverberações, é possível, ao que parece, um outro ângulo de análise para essa questão que está longe de ser descartável: dizer que há uma aproximação entre mulher e natureza e entre homem e cultural não significa, necessariamente, afirmar a distinção entre natureza e cultura. Pelo contrário, se nos colocamos novamente às voltas com essa questão é porque inúmeras teorizações já possibilitam a clareza de que jamais houve a distinção factual entre as partes do binômio. Se historicamente empregamos esses termos nos referindo a coisas distintas, foi por um equívoco gerado por nosso vício racional e linguageiro, entre tantos outros, que opera habitualmente mais por representações que por percepções dos fenômenos. 
REVISTAELETRÔNICA

DA GRADUAÇÃO/PÓS-GRADUAÇÃO EM EDUCAÇÃ O

Volume, 13, n. 2, ano, 2017

ISSN. 1807-9342

Cabe aqui uma breve digressão a respeito da representação das mulheres na história de comunidades alheias às representações ocidentais, pontuados com os problemas derivados da separação entre natureza e cultura. Podemos destacar, nesse encaminhamento, as considerações feitas por Raminelli (2015) acerca das representações constituídas por europeus a respeito das mulheres ameríndias. Nessas representações, havia já uma dualidade: as características positivas associadas aos resquícios da natureza numa imagem edênica próxima do Gênesis da Bíblia; de outro lado, as características associadas à perdição atribuídas ao diabo, como o canibalismo, as guerras e a libertinagem.

Em várias tribos indígenas, os papéis de gênero não seguiam a mesma organização hierárquica que na cultura ocidental, de forma que várias delas eram organizadas em torno da figura da mulher, sendo as mesmas proprietárias de terras, do gado, e tomadoras de decisões. Muitas mulheres foram retratadas como deusas, videntes e conselheiras na própria mitologia tradicional indígena. Após a invasão dos europeus, as instituições indígenas assumiram formatos sintonizados com a visão patriarcal dos colonizadores, de forma que as mulheres indígenas tiveram de lutar não somente contra a imposição de uma cultura ocidental, mas também contra a perda de status que as instituições colonizadoras tentavam impor aos sujeitos femininos nativos (SCHNEIDER, 2002. p. 47).

Uma questão abordada por Ronald Raminelli em seu artigo Eva Tupinambá é a associação dessa degradação moral à imagem das velhas índias no imaginário europeu. Para Raminelli, a forma como os visitantes - em forma de relatos escritos ou pinturas -, retratavam as velhas índias, remetiam diretamente à dicotomia levantada pelo homem entre Natureza e Cultura. Dessa forma, para o autor:

\footnotetext{
Existem sutis diferenças entre jovens e velhas

Degradação fisiológica: a falta de dentes obriga as velhas a recorrerem a alimentos em estado natural, alimentos crus, ao passo que as jovens podem comer carne assada, isto é, alimentos transformados pelo homem, pela cultura.

Regressão cultural: a falta de ornamento e cuidado com o corpo aproxima as velhas da natureza, dos animais; as jovens, por sua vez, modelam seus corpos e utilizam adereços, indícios de civilização.

Regressão fisiológica e cultural: o corpo das velhas retrata a ação da natureza sob o ser humano, o desgaste e a degradação física; as jovens, no entanto, mantêm seus corpos dentro de um ideal de beleza. Desse modo, aproximam-se mais de um modelo civilizacional. (RAMINELLI, 2015. p. 40).
}

É nessa base negativante da natureza que se desenvolve a história das mulheres nas Américas. Da degradação do corpo, meio pelo qual a mulher é, a um só tempo, contraída na dimensão da natureza e incluída na dinâmica social no seu papel de reprodutora, resulta também 


\section{ITINERARIUS REFLECTIONIS}

Volume, 13, n. 2, ano, 2017
DA GRADUAÇÃO/PÓS-GRADUAÇÃO EM EDUCAÇÃO

ISSN. 1807-9342

uma regressão cultural. Os papéis a que fora destinada, intimamente associados à corporeidade, perdem-se na velhice. Por não ter propriedade sobre seu projeto historial, sua finalidade se esgota no próprio limite da corporeidade.

Em todo tempo, no entanto, há escapes que reclamam a superação dessas representações. $\mathrm{Na}$ antropologia e etnologia, o matriarcado foi recorrentemente considerado uma forma primitiva de organização social.Em textos produzidos por escritoras indígenas contemporâneas, as personagens femininas indígenas em sua maioria são ainda individualmente dotadas de poder e respeito, obtendo-os graças aos conhecimentos que detém em relação às tradições de sua tribo. No entanto, essas personagens são constituídas sem nenhuma autoridade, já que essa autoridade precisa ser legitimada por instituições e reconhecida dentro dos padrões da cultura dominante. No universo imaginário imposto, marcado por uma perspectiva cristã, a percepção das índias tupinambás pelos viajantes se compunha de uma visão misógina, onde era comum a ênfase à fragilidade moral das mulheres, enquanto a dedicação do homem à caça e à pesca mantinha-o longe das tentações. Heranças da imagem de Eva, abertura à danação e ao pecado na tradição cristã.

A história da ciência antropológica precisou romper com sua primeira teoria sobre diferença cultural - a ideia evolucionista - onde tudo que se aproxima da natureza é considerado rudimentar, primordial, selvagem. O uso do termo "cultura" é algo que suscita, de imediato, a suspeita de uma hierarquia que legitima e atrai outros termos próprios desses resquícios: civilização, desenvolvimento, complexidade. A transposição teórica da distinção entre natureza e cultura no tratamento dos fenômenos humanos se dá com o reconhecimento das singularidades e complexidade de sociedades antes ligadas mais à dimensão da natureza.

Tudo se passa como se o conceito de cultura estivesse intimamente ligado ao de humanidade. O humano só poderia ser definido a partir da superação de sua própria natureza animalidade, selvageria -, de forma que a prova de sua condição humana só surgiria a partir da demonstração de sua condição cultural. É nesse sentido que Velho \& Castro $(1978$, p.3) destacam que "a Cultura ergue-se como a instância propriamente humanizadora, que dá estabilidade às reações comportamentais, e funciona como o mecanismo adaptativo básico da espécie”. Os elementos necessários para superação do evolucionismo advêm da constatação de que essa estabilização "se caracteriza por ser não-determinada universalmente". No entanto, o que importa aqui é a ideia de que nada se pode impor à facticidade do mundo que tenha sido produzido como esforço conceitual. O humano jamais deixou sua natureza porque foi capaz de 
REVISTAELETRÔNICA DA GRADUAÇÃO/PÓS-GRADUAÇÃO EM EDUCAÇÃ O

ISSN. 1807-9342

Volume, 13, n. 2, ano, 2017

constituir suas culturas. Ele mesmo é a prova de inseparabilidade entre o que nomeou natureza e cultura e ambas têm a provisoriedade de qualquer elaboração conceitual: "a natureza, seja no nível das células, organismos, ecossistemas ou do planeta, parece ser tão 'fugaz' quanto a sociedade, minando qualquer tentativa de separar os dois domínios analíticos e teóricos em termos de escalas de tempo diferentes" (PALSSONapud PITROU, 2015, p.184).

Nesse contexto, destacamos as reflexões de Ingold (1994) que aponta a influência das ciências naturais na forma como etólogos e sociólogos identificam a natureza humana com o que existe de animal no humano, nele encoberta pelos acréscimos da cultura. De outro lado, a ciência antropológica opera a substituição da noção de espírito pela aptidão para a cultura. Se assim a distinção entre humano e outros seres se justifica pela cultura, colocada em oposição ao plano da natureza, ele mesmo se transforma em um conflito entre animalidade e humanidade.

As discussões teóricas atuais concluem recorrentemente sobre a inseparabilidade entre natureza e cultura. Não obstante, esse conflito permanente entre animalidade e humanidade prova que estamos longe da suposta superação do pensamento dual. Falamos como se fora o bastante concluir pela inseparabilidade entre natureza e cultura para superar a sobreposição da representação dual na leitura dos fenômenos humanos. Trata-se de uma condição meio paradoxal: os fenômenos servem de argumento na defesa da indistinção natureza e cultura, mas, mergulhados neles, os grupos humanos ainda falam muito mais da dimensão com que historicamente se identificaram, a saber, a cultura.

Já podemos, a custa de muitas provocações a respeito da indissociabilidade entre natureza e cultura, recusar muitos efeitos dessas representações. Associar a mulher à natureza e o homem à cultura, na perspectiva atual de uma unidade natureza-cultura, resulta um compartilhamento inevitável entre o que denominamos mulher e o que denominamos homem. Vê-se que da exclusão de uma dualidade, depreende-se a disfunção de outra a ela associada. Atentemos: não se trata de uma fusão onde as singularidades estão subsumidas. Discutiremos a impossibilidade de fusão ingênua entre animal humano e não-humano, que também pode ser tomada em analogia à questão das singularidades mulher-homem. Trata-se de evidenciar e legitimar as zonas de compartilhamento e indeterminação que existem entre as partes, porque delas se pode depreender a impossibilidade de exercícios de contenção de umas sobre as outras, de jogos de poder de onde resultam impedimentos de uns sobre outros, de uma hierarquia que jamais pode se justificar nas singularidades, senão na visão do outro como outro radical. Portanto, se revisitamos aqui os termos natureza e cultura e as dualidades a ele associadas, é 
REVISTAELETRÔNICA

DA GRADUAÇÃO/PÓS-GRADUAÇÃO EM EDUCAÇÃ O

ISSN. 1807-9342

Volume, 13, n. 2, ano, 2017

para denunciar o mau uso dos termos e o que está por trás dele: o tratamento das representações da diferença em prol de práticas intelectuais e sociais excludentes.

\subsection{A natureza adestrada}

As reflexões Ortner, entre as décadas de 70 e 80, tiveram grande impacto por apontarem não exatamente para a separação entre natureza e cultura, ou para a ligação da mulher com a natureza, mas por destacar as justificativas que levaram historicamente as sociedades a admitirem ambas as representações. Garcia (2009, p.97) destaca outras provocações nessa esteira: "Carolyn Merchant ou Yniesta King, defendem que os binômios natureza-cultura e mulher-homem são falsos, foram construídos pelo sistema patriarcal para manter uma hierarquia entre os sexos/gêneros e natureza/cultura". São falsos, mas ainda assim, se encravaram em práticas e discursos e guardam ressonâncias na atualidade.

$\mathrm{Na}$ crítica tecida às provocações de Ortner, assim como nas dirigidas a Beauvoir, se destaca o possível equívoco de partir da separação de natureza e cultura para associar a mulher à primeira e o homem à segunda, o que resultaria um inevitável sexismo. No entanto, o que estava em questão em seus argumentos era justamente a necessidade de transposição das ideias sobre as quais se podia ancorar um dualismo travestido de uma condição hierárquica. Ortner (1979, p.100) destaca o caráter de mera síntese intelectual da distinção entre cultura e natureza: “as categorias de 'natureza' e 'cultura', certamente, são categorias conceituais - não se pode encontrar limite no mundo concreto entre os dois estados ou domínios do ser". Dessa forma, nenhum efeito gerado na classificação de inferior e superior podem se justificar a partir de numa mera síntese intelectual.

É justamente esse aspecto que precisamos analisar: se os discursos e práticas sociais que testemunhamos em nossa atualidade demonstram rupturas efetivas com essas justificativas que legitimaram a aproximação da mulher e da natureza. Entre as justificativas, Ortner (1979, p.100) destacou: o determinismo biológico e a lógica do sexo dominante; a identificação com algo que a cultura desvaloriza - a natureza -, que coloca como ordem inferior a si própria. É, nesse sentido, a partir de um discurso autorreferente, que o homem dá a si a ideia de sua superioridade: um ser cultural, que transcendeu os limites da pura natureza. Dessa forma, ainda que não haja distinção efetiva entre natureza e cultura, ela se mantém implícita nas 
REVISTAELETRÔNICA

DA GRADUAÇÃO/PÓS-GRADUAÇÃO EM EDUCAÇÃ O

ISSN. 1807-9342

Volume, 13, n. 2, ano, 2017

representações sociais e a cultura transita ainda nos discursos como a possibilidade de transcendência das condições naturais.

Resta nos perguntarmos até que ponto essa forma de enxergar a mulher atrelada a seus corpos reprodutores foi desnaturalizada para homens e mulheres nos dias atuais. Obviamente, estamos longe das justificativas de uma sociedade que tomava o útero da mulher negra para fundar sua escravidão e alimentar o sistema escravista: "enel caso de lasesclavastambiénel uso de sus cuerpos para servir a laregeneración de laesclavitudpuedeconsiderarseviolencia física y psicológica que al mismotiempo propicia suanimalización”. (CANCELAS, 2014, p.237). De outro lado, é ainda o Estado que regra tanto a vida social da família biológica quanto o uso que a mulher faz do próprio corpo, por exemplo, proibindo-a de esterilizar-se ainda que tenha plena convicção de não desejar atender à finalidade da reprodução.

A lógica do dualismo precisa ser superada, sem o que as separações hierárquicas entre mulher e homem, humano e animal, natureza e cultura, não deixarão de causar ressonâncias em discursos e ações. Sem isso, ainda compreenderemos facilmente cenários como o descrito por Gersão:

\begin{abstract}
Mas também há coisas para mudar em África [...] Os ódios entre negros, por exemplo, ou a forma como as mulheres são tratadas: carregam os filhos, a água, a lenha, o homem ao lado, a caminhar como um reio, e ela carregando tudo, como burro de puxar carroça. Trabalham de sol a sol e quando calha são espancadas pelos homens, às vezes casam sem amor, só porque convém à família, e depois a melhor comida é par ao marido: quando ele se senta à mesa ela não se senta com ele, come depois os restos, e se for o caso também a sobra manda nela e lhe bate. Por isso às vezes acontecem coisas, as mulheres fogem, deitam-se ao rio, vão procurar os crocodilos, enforcam-se nas árvores ou fogem mato adentro até caírem de fome de sede e de cansaço. (GERSÃO, 2004, p.162).
\end{abstract}

É, portanto, temeroso abandonarmos definitivamente a questão: "Existe uma conexão histórica entre a dominação da natureza e a mulher" (GARCIA, 2009, p.96), sem antes termos esgotado as provas históricas e contextuais da submissão.

No texto Na terra de Deus e do Homem, Silvana Paternostro (1999) aponta questões bastante controversas sobre a sexualidade da mulher. Arriscamos considerar que, nos anos que se seguiram às suas considerações, pouco dos alvos das suas provocações mudou. Na sua crítica à cultura sexual, aponta a forma como mulheres latino-americanas ainda tomam para si discursos sobre: a necessidade de preservação da virgindade para conseguir bons casamentos, o que explica o sucesso de clínicas de estética que oferecem o procedimento de reconstituição do hímen; a dispensa do uso de preservativos em relações consideradas estáveis, em sociedades 
REVISTAELETRÔNICA

DA GRADUAÇÃO/PÓS-GRADUAÇÃO EM EDUCAÇÃ O

ISSN. 1807-9342

Volume, 13, n. 2, ano, 2017

onde comprovadamente a maioria das mulheres soropositivas, contraíram HIV de seus maridos; a exclusão, travestida de tolerância, de homo e trans sexuais com a justificativa de que não podem garantir a perpetuação da sociedade, embora muitos homens autodenominados heterossexuais admitam terem relações homoafetivas; o tratamento diferencial de iniciação sexual entre garotas e garotos, que perduram como cuidados inevitáveis na formação da mulher.

São denúncias da permanência do discurso machista que reverbera na boca de mulheres condicionadas ao tradicionalismo moral. Como prova gritante dessa atualidade, Paternostro (1999, p.302) cita uma escola de Assunción onde as garotas, para se formarem, "tinham que apresentar não uma tese final, mas uma 'canastilla de bebé', um enxoval completo para uma criança que vai nascer", sendo que tanto os pais quanto as alunas "achavam que este era um projeto e um trabalho digno de mérito".

Consideremos... Quase uma década se passou e as mudanças são consideráveis, mas não o bastante para impedirem que em bairros de classe médio-alta de cidades populosas no Brasil, como São Paulo, Belo Horizonte, Uberaba e Uberlândia, nasçam escolas de princesas, que só admitem meninas, de quatro a quinze anos, que precisam ser preparadas para serem mulheres completas, o que inclui as tarefas de cuidados com o lar. A fórmula da mulher completa é cuidadosamente perseguida pelo currículo proposto que inclui: identidade de princesa; relacionamentos de princesa; estética de princesa; etiqueta de princesa; castelo de princesa e evolução de princesa a rainha (disponível em www.escoladeprincesas.net). Os conteúdos do item identidade preveem os conceitos da vida de princesa, seu caráter interno, princípios éticos e morais, o sonho da princesa ou seu destino, além de exemplos de princesas reais e fictícias. Aos modelos de relacionamento previstos no item Relacionamentos de princesa, somam-se recomendações para espera do príncipe e a restauração dos valores morais do matrimônio no item Evolução de princesa a rainha, depois de ter passado pelos conteúdos do tópico Castelo de princesa: limpeza, organização e funcionamento do ambiente; educação financeira; mordomia e prendas da princesa, como corte e costura, culinária básica, lavanderia, primeiros socorros. Tal pedagogia de princesa foi constituída a partir de um sonho da idealizadora:

Da idealização da escola, que nasceu por meio de um sonho - literalmente: ela uma noite sonhou com um lugar em que ensinava tudo isso a meninas de variadas idades -, até a sua abertura foram oito meses de planejamento, escolha do local de funcionamento e registro de marcas registradas e patentes, uma vez que não havia nada parecido com isso no mundo (PAULINO, 2013, s/n). 
REVISTAELETRÔNICA

DA GRADUAÇÃ O/PÓS-GRADUAÇÃO EM EDUCAÇÃ O

ISSN. 1807-9342

Volume, 13, n. 2, ano, 2017

O velho destino de reclusão no óikos desenhando a histórias de mulheres do século XXI...

\subsection{A sistemática do devir: outra armadilha}

O corpo de Mendieta poderia ser qualquer corpo, não necessariamente um corpo dito nu, dito fêmea. Um corpo que não se define e nem é definido. Um corpo-naturezacultura,subversivo de uma ou outra Cultura. Ele já se desfez dos adereços que o fazem refém de um conceito de mulher. Não tem mais compromisso com a domesticação da animalidade. Não está pintado, aos moldes de uma cultura, para ser menos selvagem e mais humano. Não é o corpo na experiência da mulher que "faz-se planta, pantera, diamante, madrepérola, misturando a seu corpo flores, peles, búzios, penas", tentando com isso "esconder a crueza animal de sua carne, de seu odor" (BEAUVOIR, 1970, p.201). Ao contrário, é um corpo movido pelas próprias potências e não por um projeto,que está,juntamente com as flores, as peles, as penas, encravado na paisagem, na carnalidade do mundo, comungando suas vitalidades e sua tendência à morte.

Voltemos à Ortner (1979). Quando ela se pergunta por que as mulheres se parecem mais próximas da natureza, cita o corpo. Não poderia ser diferente, já que a corporeidade é o alvo dos regimes de contenção necessários à humanização. Ortner (1979, p.102-105) destaca o fato de que o corpo da mulher ser lido como um corpo para, como dão prova os seios e os ovários destinados à reprodução. Essa consideração ela faz na esteira do pensamento beauvoiriano: "pela invenção da ferramenta, a manutenção da vida tornou-se para o homem atividade e projeto, ao passo que na maternidade a mulher continua amarrada a seu corpo, como o animal" (BEAUVOIR, 1970, p. 86). O reconhecimento do corpo assim direcionado a uma finalidade reforça a aceitação quase universal da mulher de que parte de sua existência precisa ser orientada a essa função. Apesar dos avanços já alcançados em dias atuais, essa função representa ainda, em alguma medida, sua limitação a certos contextos sociais. $\mathrm{O}$ corpo que reproduz está ou bem sacralizado por sua singular importância, ou bem condenado, por sua tendência à perdição.

Mas poderia ser esse corpo de Mendieta um corpo não re-producente. Um corpo com seios, útero, com um rosto coberto de pelos (MENDIETA, Untitled, Facial HairTransplants, 1972)... Um corpo producente. Ou um corpo sem seios, útero ou pelos. Um corpo com testículos 
REVISTAELETRÔNICA

DA GRADUAÇÃO/PÓS-GRADUAÇÃO EM EDUCAÇÃ O

ISSN. 1807-9342

Volume, 13, n. 2, ano, 2017

e seios. Um corpo... Estranho? O termo é imediato porque imediata é a subsunção dos espaços de compartilhamento e indeterminação na lógica caduca da nomeação, do padrão dual. Daí por diante, não tardam os esforços de identificação dispendidos pelos que precisam da determinação da alteridade e daqueles que querem se identificar em qualquer parte de um discurso desnecessário, sem materialidade.

Há certa urgência em falarmos em nome de uma desnecessária defesa da diferença, simplesmente porque, na vigência da ideia de diferença, próxima a estranhamento, nenhum passo foi dado na superação dos dualismos fundamentais. Isso não é pouco. Nosso insistente universo representativo, aquela dimensão de cultura que nós mesmos forjamos como descolada da materialidade do mundo, tem estimulado preconceitos, violências e mortes. O contorno desse horrendo quadro não está somente na luta contra o preconceito, mas na visibilidade do pouco do humano e de onde esse pouco esteve sempre mergulhado em compartilhamentos e não em distinções.

A sociedade focada no esforço da nomeação, no lugar de respeitar os espaços de indeterminação, reforça a distinção entre natureza e cultura. Ainda quando se fala contra a separação entre natureza e cultura, não se evita a classificação dos tipos.Até o discurso em defesa das diferenças acaba, muitas vezes, por admitir uma prática de nomeação e qualificação do Outro. No limite, podemos dizer que até o discurso sobre gêneros recai, às vezes, na armadilha desse contrassenso, quando estimula, em alguma medida, o padrão identificador, a conformação do ser a isso ou aquilo, a condenação do corpo à imagem, às tipologias admitidas não mais somente na dualidade feminino-masculino, mas em uma gradação de inúmeros tipos de subjetivações ainda encerradas na lógica de dualidade, do "entre". Algo parecido com os organogramas de sistematas que teimam em cavar tipos onde só encontram, fascinados, vez ou outra, uma forma rebelde...

Em um conto de Júlio Cortázar, Sua fé nas ciências, o empenho do sistemataé ridicularizado por uma sequência de tentativas inglórias de classificar uma profusão de formas:

Uma esperança acreditava nos tipos fisionômicos, tais como os de nariz achatado, os de cara de peixe, os de cara grande tomada de ar, os amarelados e os sombrancelhudos, os de cara intelectual, os de estilo cabeleireiro, etc. Disposto a classificar definitivamente esses grupos, começou a fazer grandes listas de conhecidos e os dividiu nos grupos acima mencionados. Tomou então o primeiro grupo, integrado por oito rapazes de nariz achatado e percebeu com surpresa que na realidade eles se subdividiam em três grupos, isto é: os de nariz achatado bigodudos, os de tipo boxeador, os estilo contínuo de Ministério, composto respectivamente por 3,3 e 2 narizes achatados. Apenas os separou em seus novos grupos (...) percebeu que o primeiro subgrupo não era igual, porque os dois bigodudos de nariz achatado pertenciam ao tipo capivara, enquanto o restante era com toda certeza umnariz 
Volume, 13, n. 2, ano, 2017

achatado de corte japonês. Afastando-o com a ajuda de um bom sanduíche de enchova e ovo cozido, organizou o subgrupo das não capivaras, e se dispunha a inscrevê-lo em seu caderno de trabalhos científicos quando uma das capivaras olhou para o lado oposto, em consequência do que a esperança e os demais candidatos puderam perceber que, enquanto a primeira capivara era evidentemente um nariz achatado braquicéfalo, a outra possuía um crânio muito mais apropriado para pendurar um chapéu que para encaixá-lo. Assim que se dissolveu o subgrupo, e do resto nem é bom falar porque os demais sujeitos haviam passado do mazagrán à cachaça queimada, e a essa altura dos acontecimentos a única semelhança entre eles era o firme propósito de continuarem bebendo às custas da esperança (CORTÁZAR, 1994, p.138-139)

Deixemos a mania de determinação às esperanças, aos cientistas, ainda que os efeitos de suas classificações sejam também redutores, como aponta Derrida (2011), em O animal que logo sou, ao sugerir o termo Animot para contornar a incoerência de agrupar no nome "animal" uma infinita variedade de viventes marcados pela suposta faltadas características que os definiriam como humanos.

Pensemos em todos os corpos que aceitam os desenhos das pulsões que identificamos como femininas. Tornam-se alvos das mesmas resistências e questionamentos direcionados à mulher. Aproximam-se, como elas, da animalidade, assumindo a vulnerabilidade de um puro devir orgânico. Ainda que neles sejam identificadas muitas faltas, no inevitável exercício de comparação com o conceito de mulher estabelecido, são também vítimas de agressões corretivas e de discursos coercitivos que não aceitam mais que seus próprios conceitos.

\section{Considerações finais}

O tema é, assim, recorrente. Não faltam em nossa história, elementos que demonstram a solidez desses conceitos excludentes. Ainda temos preconceitos. Se não tivéssemos, não precisaríamos do conceito de diferença e dos argumentos de aceitação dela.Ainda não chegamos lá. Ainda dizemos que não somos todas(os) animais. Ainda não desejamos ser todas(os) o confuso entrelaçamento natureza-cultura. Resta-nos desmancharmos nossos discursos e cuidarmos para que não povoem, insistentes, nossas novas composições linguageiras e existenciais.

Evidenciem-se outros corpos híbridos, indetermináveis, producentes, em chamas. Dancem a dança do enlouquecimento, da perda de referências, da suspensão dos pudores, envoltos em tramas. Que eles não sejam tão arquitetados, mas que seus desenhos se formem e se desfaçam nos movimentos involuntários, alimentados por suas próprias potências.Indiferentes. 
Volume, 13, n. 2, ano, 2017

\section{Referências}

BEAUVOIR, Simone. O segundo sexo. 1. Fatos e Mitos. $4^{\mathrm{a}}$ ed. Difusão Europeia do Livro, Paris: Gallimard, 1970.

CANCELAS, Carla R. (2014). ExancillanatusEsclavitudfemenina y reproducción biológica.Asparkía, v.25, pp. 232-237.

CIDRE, Elza Rodríguez. (2014). Mujeres, animales y sacrificioen Bacantes de Eurípides. Asparkía, v.25, pp. 19-32.

CORTÁZAR, Júlio. História de cronópios e de famas. Trad. Gloria Rodriguez. $5^{\text {a }}$.ed. Rio de Janeiro: Civilização brasileira, 1994.

DEBERT, Guita G.; ALMEIDA, Heloisa B. Entrevista com SherryOrtner. Cadernos Pagu, v.27, pp.427-447, julho-dezembro de 2006.

DERRIDA, Jacques. O animal que logo sou. Trad. Fábio Landa. 2 ed. São Paulo: Editora Unesp, 2011.

DESCOLAS, Philippe. As lanças do crepúsculo: relações Jivaro na Alta Amazônia. Trad. Dorothée de Bruchard. São Paulo: Cosac \&Naify, 2006.

DESCOLAS, Philippe. Estrutura ou sentimento: a relação com o animal na Amazônia. Mana, v.4, n.1, pp.23-45, 1998.

GARCIA, Loreley. Ecofeminismo: Múltiplas Versões. Revista Ártemis. Vol. 10, Jun 2009, p. 96-118.

GERSÃO, Teolinda. As árvores das palavras. São Paulo: Editora Planeta do Brasil, 2004. HEARTNEY, Eleanor. Rediscovering Ana Mendieta.Art in America. New York, v.92, pp,139-194, November, 2004.

HEIDEGGER, Martin.Os conceitos fundamentais da metafísica. Rio de Janeiro: Forense Universitária, 2006.

INGOLD, Tim. Humanity and Animality. In: Tim Ingold (ed.), Companion Encyclopedia of Anthropology. Londres: Routledge, 1994, pp. 14-32.

MENDIETA, Ana. Siluetas Series. Imagen de Yagul, 1973. Disponível em: http://www.sfmoma.org/explore/collection/artwork/9152, Acesso em 20 de junho de 2015.

Untitled, Facial HairTransplants, 1972. Disponível em: http://collection.louisiana.dk/asset-viewer/untitled-facial-hair-transplants-performanceiowa/fgEBvPgAYsr13g, Acessado em 30 de janeiro de 2017. 
REVISTAELETRÔNICA

DA GRADUAÇÃO/PÓS-GRADUAÇÃO EM EDUCAÇÃ O

ISSN. 1807-9342

Volume, 13, n. 2, ano, 2017

. San Felipe, Fotografia de Ana Mendieta, 1973. Disponível em: http://filamentosmovimentos.blogspot.com.br/2007_07_01_archive.html, Acesso em 30 de janeiro de 2017.

Feathers on a woman, 1972.Disponívelem: http://www.learn.columbia.edu/courses/fa/htm/fa_ck_mendieta_1.htm. Acesso em 20 de junho de 2015.

Rape $\quad$ Scene, $1973 . \quad$ Disponível em: http://www.learn.columbia.edu/courses/fa/htm/fa_ck_mendieta_1.htm. Acesso em 20 de junho de 2015.

ChickenPiece,

1972.

Disponível

em:

http://www.alisonjacquesgallery.com/artists/47-ana-mendieta/works/9120/. Acesso em 20 de junho de 2015.

Alma SiluetaenFuego. Silueta de Cenizas, 1975. Disponível em: http://www.alisonjacquesgallery.com/artists/47-ana-mendieta/works/9116/. Acesso em $20 \mathrm{de}$ junho de 2015.

ORTNER, Sherry B. Está a mulher para o homem assim como a natureza para a cultura? In: ROSALDO, Michelle e LAMPHERE, Louise. A Mulher, a cultura, a sociedade. Rio de Janeiro, Paz e Terra, 1979.

PATERNOSTRO, Silvana. Na terra de deuses e do homem. Rio de Janeiro: Editora Objetiva, 1999.

PAULINO, Raquel. Escola de princesas recua no tempo e ensina meninas a ter 'bons modos'. 2013.Disponível em: http://delas.ig.com.br/filhos/2013-09-04/escola-de-princesasrecua-no-tempo-e-ensina-meninas-a-ter-bons-modos.html, acessado em 30/01/3017.

PITROU, Perig. Uma antropologia além de natureza e cultura? Maná, v.21, n.1, pp. 181-194, 2015.

RAMINELLI, Ronald. Eva tupinambá. In: PRIORE, M. D. História das mulheres no Brasil. São Paulo: Contexto, 2015. 10. ed., $3^{\text {a }}$ reimp. 678 p.

SCHMIDT, Elisa. Ana Mendieta - Cenas sacrificais entre o humano e o animal. Revista Da Pesquisa, UDESC, Florianópolis/SC, n.7, pp.103-111, ago2009-jul 2010.

SCHNEIDER, Liane. Escritoras americanas de origem indígena: Que mulheres são essas? In: SANTOS. Luísa Cristina dos. Literatura e Mulher: das linhas às entrelinhas. Ponta Grossa: Editora UEPG, 2002. 1. ed., 200 p.

VALENTIM, Marco A. Extramundanidade e sobrenatureza: para uma crítica da antropologia filosófica. In: I Encontro de Fenomenologia: Fenômeno/Mundo, 2012. Disponível em: http://www.academia.edu/9064664/Extramundanidade_e_sobrenatureza, Acessado em $30 / 01 / 2017$. 


\section{ITINERARIUS REFLECTIONIS}

\section{REVISTAELETRÔNICA}

DA GRADUAÇÃ O/PÓS - GRADUAÇÃO EM EDUCAÇÃ O

ISSN. 1807-9342

Volume, 13, n. 2, ano, 2017

VELHO, G.; CASTRO, E. O conceito de cultura e o estudo de sociedades complexas: uma perspectiva antropológica. Artefato, ano 1, $\mathrm{n}^{\circ} 1$, 1979. Disponível em: http://docslide.com.br/documents/conceito-de-cultura-em-sociedades-complexas.html, Acessado em 30 de janeiro de 2017.

VIVEIROS DE CASTRO, Eduardo. Os pronomes Cosmológicos e o perspectivismo ameríndio. Maná, v.2, n.2, pp.115-144, 1996. 